\title{
Transcriptome sequencing and metabolome analysis of food habits domestication from live prey fish to artificial diets in mandarin fish (Siniperca chuatsi)
}

\author{
Shan He ${ }^{1,2,3}$, Jun-Jie You ${ }^{1,2,3}$, Xu-Fang Liang ${ }^{1,2^{*}}$, Zhi-Lu Zhang ${ }^{1,2}$ and Yan-Peng Zhang ${ }^{1,2}$
}

\begin{abstract}
Background: As economical traits, food habits domestication can reduce production cost in aquaculture. However, the molecular mechanism underlying food habits domestication has remained elusive. Mandarin fish (Siniperca chuatsi) only feed on live prey fish and refuse artificial diets. In the present study, we domesticated mandarin fish to feed on artificial diets. The two groups were obtained, the fish did not eat artificial diets or ate artificial diets during all of the three domestication processes, named Group W or X, respectively.

Results: Using transcriptome and metabolome analysis, we investigated the differentially expressed genes and metabolites between the two groups, and found three common pathways related to food habit domestication, including retinol metabolism, glycerolipid metabolism, and biosynthesis of unsaturated fatty acids pathways. Furthermore, the western blotting and bisulfite sequencing PCR analysis were performed. The gene expression of TFIIF and histone methyltransferase ezh1 were significantly increased and decreased in the fish of Group X, respectively. The total DNA methylation levels of TFIIF gene and tri-methylation of histone H3 at lysine 27 (H3K27me3) were significantly higher and lower in the fish of Group X, respectively.

Conclusion: It was speculated that mandarin fish which could feed on artificial diets, might be attributed to the lower expression of ezh1, resulting in the decreased level of H3K27me3 and increased level of DNA methylation of TFIIF gene. The high expression of TFIIF gene might up-regulate the expression of genes in retinol metabolism, glycerolipid metabolism and glycerophosphoric metabolism pathways. Our study indicated the relationship between the methylation of DNA and histone and food habits domestication, which might be a novel molecular mechanism of food habits domestication in animals.
\end{abstract}

Keywords: Mandarin fish, Transcriptome sequencing, Metabolome, H3K27 tri-methylation, DNA methylation, Food habits domestication

\footnotetext{
* Correspondence: xfliang@mail.hzau.edu.cn

'College of Fisheries, Chinese Perch Research Center, Huazhong Agricultural University, 1 Shizishan Street, Wuhan 430070, Hubei, China

${ }^{2}$ Innovation Base for Chinese Perch Breeding, Key Lab of Freshwater Animal Breeding, Ministry of Agriculture, Wuhan 430070, China

Full list of author information is available at the end of the article
}

C C The Author(s). 2021 Open Access This article is licensed under a Creative Commons Attribution 4.0 International License, which permits use, sharing, adaptation, distribution and reproduction in any medium or format, as long as you give appropriate credit to the original author(s) and the source, provide a link to the Creative Commons licence, and indicate if changes were made. The images or other third party material in this article are included in the article's Creative Commons licence, unless indicated otherwise in a credit line to the material. If material is not included in the article's Creative Commons licence and your intended use is not permitted by statutory regulation or exceeds the permitted use, you will need to obtain permission directly from the copyright holder. To view a copy of this licence, visit http://creativecommons.org/licenses/by/4.0/. The Creative Commons Public Domain Dedication waiver (http://creativecommons.org/publicdomain/zero/1.0/) applies to the data made available in this article, unless otherwise stated in a credit line to the data. 


\section{Background}

Food habits domestication can reduce production cost in animals. Mandarin fish, as an economic species, has very unique food preference. In the wild, as soon as they start to feed, they feed exclusively on live fry of other fish species [1]. Our previous study showed transcriptome determining of food preference (dead prey fish), and indicated that retinal photosensitivity, appetite control, circadian rhythm, learning and memory outputs might be involved in the food habit domestication of dead prey fish [2]. Compared to dead prey fish, the domestication of mandarin fish to accept artificial diets can provide more profitability. However, little studies investigate the molecular regulatory mechanisms of the domestication to accept artificial diets in mandarin fish.

Previous research showed that the hormones from central nervous systems play important roles in the food intake control, such as neuropeptide $\mathrm{Y}(N P Y)$ and agouti-related protein $(A g R P)[3,4]$. In giant panda, Tas1r1 pseudogenization reinforced the herbivorous life style because of the diminished attraction of returning to meat eating in the absence of Tas1r1 [5, 6]. The ion channels polycystic kidney disease 1-like 3 (PKD1L3) and PKD2L1 linked to sour taste, and the integral membrane protein CD36 is a putative "fat taste" receptor [7]. In a leaf-eating colobine monkey, metabolism genes pancreatic ribonuclease gene (RNASE1) was contributed to its food habits (leaves) [8]. However, little is known about the genetic and metabolic regulation on the food habits domestication of mandarin fish.

It has been noted that epigenetic status might be modified by environment and diets [9]. In mice, by feeding the diets with high levels of methyl donors (e.g. folic acid) to pregnant dams, it was possible to modify the expression of the agouti gene in the offspring with the high levels of DNA methylation [10, 11]. Histone modifications correlate with transcriptional activation and repression. The maternal undernutrition led to a decreased H3K $27 \mathrm{me} 3$ level of the promotor region and increased expression of pomc gene in offspring mice [12]. Therefore, whether epigenetic regulation plays an important role in the food habits domestication is unknown.

In the present study, we domesticated the mandarin fish to accept artificial diets, and conducted the transcriptome sequencing and metabolome analysis to search the common pathways of transcriptome sequencing and metabolome. In addition, using western blotting and bisulfite sequencing PCR, we examined the methylation of histone and DNA, to investigate the molecular mechanism of food habits domestication in mandarin fish, which could promote the culture of mandarin fish with artificial diets.

\section{Results}

Pathway classification map of the differentially expressed genes based on transcriptome sequencing

The cDNA libraries were constructed from $\mathrm{W}$ and $\mathrm{X}$ groups of mandarin fish, and sequenced using the Illumina Hiseq2000 system. High quality reads were assembled. After removing the partial overlapping sequences, a total of 77,312 distinct sequences were obtained (AllUnigene, mean size: $1138 \mathrm{bp}$, N50: $2334 \mathrm{bp}$ ). In these unigene, $49.06 \%(37,927)$ were less than $500 \mathrm{bp}, 50.94 \%$ $(39,385)$ were longer than $500 \mathrm{bp}$, in which $34.38 \%$ (26, 578) were longer than $1000 \mathrm{bp}$. We found 54 genes to be differential expressed among the two groups, 29 and 25 genes are up-regulated and down-regulated in mandarin fish of Group X, respectively. The metabolic pathway showed the most differential expressed genes (Fig. 1a and b), in which lipid metabolism, signal transduction and global overview maps showed 10, 6 and 13 genes to be differentially expressed, respectively (Fig. 1a). And the rich factor of steroid biosynthesis and glycerolipid metabolism is largest of all (Fig. 1b). The details of the differential expressed genes between the two groups were presented in Table 1. The sequencing data in this study have been deposited in the Sequence Read Archive (SRA) database (accession number: PRJNA613186).

\section{Analysis of differential metabolites of two groups}

We analyzed the metabolic profiles of the two groups by LC-MS in positive (ESI+) and negative (ESI-) scan modes, and selected 9249 irons for subsequent analyses (4155 irons in ESI+ mode and 5094 irons in ESI- mode).

The normalized data were analyzed by PCA and PLS-DA with multivariate analysis. The PCA result showed the positive and negative ions from the different groups were in the two clusters, and were separated clearly by the first two components (Fig. 2a). PLS-DA result showed the clear separation of the two groups (Fig. 2b), suggesting the significant biochemical changes. The hierarchical clustering analysis (HCA) of the differential metabolites showed that Group $\mathrm{X}$ and $\mathrm{W}$ showed significant difference (Fig. 2c). The information of these metabolomic biomarkers was listed in Table 2.

To identify the metabolites, we used the freely accessible database of Kyoto Encyclopedia of Genes and Genomes (KEGG) to elucidate the putative function of the metabolites. 44 and 20 irons were identified by MS1 and MS2 level in positive mode respectively, and 24 and 11 irons in MS1 and MS2 level in negative mode respectively. The details of differential ions between the two groups were presented in Table 3. 


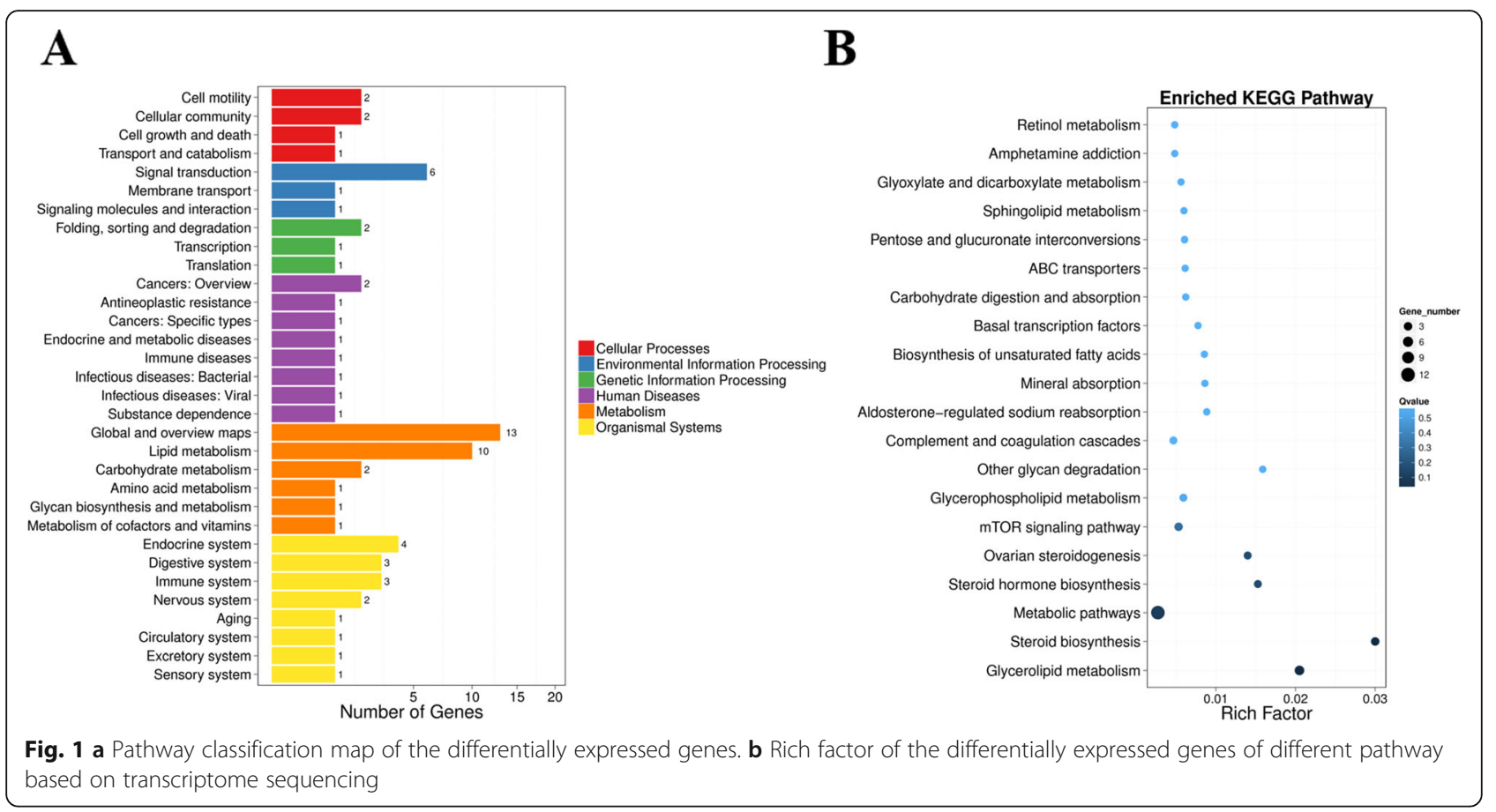

\section{The common pathways of differential metabolites and genes}

In retinol metabolism pathway, retinol, 9-cis-retinol and 11-cis-retinol metabolites were higher in mandarin fish of Group X than those of Group W, RDH (retinol dehydrogenase) gene expression was consistently higher in Group X (Fig. 3a). In glycerolipid metabolism pathway, triacylglycerol lipase gene expression was higher in mandarin fish of Group X, and glycerophosphoric metabolites was also higher in Group $X$ (Fig. 3b). In biosynthesis of unsaturated fatty acids pathway, stearoylCoA gene expression and DPA (docosapentaenoic acid) metabolites were higher in fish of Group X than those in Group W (Fig. 3c).

\section{TFIIF gene expression and DNA methylation}

As is shown in Fig. 4a, General transcription factor IIF (TFIIF) gene expression was higher in the mandarin fish of Group X than that of Group W. We then analyzed the $\mathrm{CpG}$ islands at $-5000 \mathrm{bp}$ upstream from the transcription initiation site (designated as 0 ) of TFIIF by methylation analysis software. As shown in Fig. 4b, one CpG islands containing 9 CpG sites existed in -3619 to -3574 bp of TFIIF gene. The total DNA methylation level was significantly higher in the fish of Group X than that of Group W (Table 4).

\section{Ezh1 gene expression and histone methylation}

The mRNA expression of histone methyltransferase ezh1 gene was lower in the mandarin fish of Group X (Fig. 5a). As histone methyltransferase Ezh1 could methylate 'Lys-
27' of histone H3, we analyzed the H3K27me3 levels of the two groups. The results showed that H3K27me3 level was also lower in the mandarin fish of Group $\mathrm{X}$ than that of Group W (Fig. 5b).

\section{Discussion}

In rearing conditions, mandarin fish accept only live prey fish, refusing dead prey fish or artificial diets [13]. Although pervious research showed the methods of mandarin fish domestication [14], little is known about the mechanism of food habits domestication. In the present study, we domesticated the mandarin fish to feed on artificial diets, and found a part of mandarin fish could accept artificial diets easily (Group X), but another part could not accept completely (Group W). To uncover the molecular mechanism why mandarin fish refuses artificial diets, we conducted the transcriptome sequencing and metabolome analysis. The results showed that the differentially expressed gene between the two groups were enriched in metabolism, in which the global and overview maps and lipid metabolism were the most enriched. And the rich factors of steroid biosynthesis and glycerolipid metabolism were the highest. The metabolome results showed that the pathways with different metabolites were mostly enriched in the metabolic pathways, which were consistent with transcriptome sequencing results. Previous research has shown that the most important pathways related to the domestication of dead prey fish in mandarin fish included the retinal photosensitivity, circadian rhythm, appetite control, learning and memory pathway [2]. Our results 
Table 1 Identification of differentially expressed gene based on transcriptome sequencing

\begin{tabular}{|c|c|c|c|c|c|}
\hline Gene name & $\begin{array}{l}\text { W } \\
\text { Expression }\end{array}$ & $\begin{array}{l}\mathrm{X}- \\
\text { Expression }\end{array}$ & $\begin{array}{l}\log _{2} \text { FoldChange } \\
(\mathrm{X} / \mathrm{W})\end{array}$ & KEGG map & Gene function \\
\hline $\begin{array}{l}\text { Phosphatidate } \\
\text { phosphatase LPIN1 }\end{array}$ & 43.18282 & 386.1148 & 3.160501 & $\begin{array}{l}\text { Glycerolipid metabolism, Glycerophospholipid } \\
\text { metabolism, Metabolic pathways, mTOR signaling } \\
\text { pathway. }\end{array}$ & $\begin{array}{l}\text { Generating 1,2- } \\
\text { Diacyl-sn-glycerol }\end{array}$ \\
\hline $\begin{array}{l}\text { 3-keto-steroid reductase- } \\
\text { like }\end{array}$ & 1.127324 & 20.46541 & 4.182214 & $\begin{array}{l}\text { Steroid biosynthesis, Steroid hormone biosynthesis, } \\
\text { Metabolic pathways. }\end{array}$ & $\begin{array}{l}\text { Generating 4alpha- } \\
\text { methylzymosterol } \\
\text { or Hydroxyestrone }\end{array}$ \\
\hline $\begin{array}{l}\text { general transcription } \\
\text { factor IIF subunit } 2 \\
\text { isoform X2 }\end{array}$ & 1.302917 & 25.49286 & 4.290276 & Basal transcription factors. & Transcription \\
\hline $\begin{array}{l}\text { sterol-4alpha-carboxylate } \\
\text { 3-dehydrogenase }\end{array}$ & 10.80255 & 140.7436 & 3.703626 & Steroid biosynthesis, Metabolic pathways. & $\begin{array}{l}\text { Generating 3-Keto- } \\
\text { 4-methylzymosterol }\end{array}$ \\
\hline endothelial lipase & 72.61555 & 753.4305 & 3.375124 & Glycerolipid metabolism, Metabolic pathways. & $\begin{array}{l}\text { Generating fatty } \\
\text { acid }\end{array}$ \\
\hline $\begin{array}{l}\text { serum/glucocorticoid- } \\
\text { regulated kinase } 1\end{array}$ & 1.328233 & 33.50641 & 4.656857 & $\begin{array}{l}\text { mRNA surveillance pathway, cAMP signaling pathway, } \\
\text { cGMP-PKG signaling pathway, Oocyte meiosis, Adren- } \\
\text { ergic signaling in cardiomyocytes, Vascular smooth } \\
\text { muscle contraction, Hippo signaling pathway, Focal } \\
\text { adhesion, Platelet activation, Long-term potentiation, } \\
\text { Dopaminergic synapse, Inflammatory mediator regula- } \\
\text { tion of TRP channels, Regulation of actin cytoskeleton, } \\
\text { Insulin signaling pathway, Oxytocin signaling pathway. }\end{array}$ & \\
\hline $\begin{array}{l}\text { ATP-binding cassette, } \\
\text { subfamily C (CFTR/MRP), } \\
\text { member } 12\end{array}$ & 1.067294 & 25.75915 & 4.593055 & ABC transporters. & \\
\hline stearoyl-CoA desaturase & 863.601 & $10,415.86$ & 3.592273 & $\begin{array}{l}\text { Biosynthesis of unsaturated fatty acids, Fatty acid } \\
\text { metabolism, PPAR signaling pathway, AMPK signaling } \\
\text { pathway, Longevity regulating pathway - worm. }\end{array}$ & $\begin{array}{l}\text { Fatty acid } \\
\text { desaturation }\end{array}$ \\
\hline $\begin{array}{l}\mathrm{PH} \text { domain and leucine- } \\
\text { rich repeat-containing } \\
\text { protein phosphatase }\end{array}$ & 4.106606 & 53.87121 & 3.713496 & $\begin{array}{l}\text { hospholipase D signaling pathway, Neuroactive } \\
\text { ligand-receptor interaction, Glutamatergic synapse }\end{array}$ & \\
\hline $\begin{array}{l}\text { Retinol dehydrogenase } \\
12\end{array}$ & 7.270524 & 99.28454 & 3.771438 & Retinol metabolism, Metabolic pathways & $\begin{array}{l}\text { Generating all-trans- } \\
\text { Retinal }\end{array}$ \\
\hline $\begin{array}{l}\text { lymphokine-activated } \\
\text { killer T-cell-originated } \\
\text { protein kinase homolog }\end{array}$ & 6.070951 & 145.7947 & 4.585872 & Pancreatic secretion, Protein digestion and absorption & \\
\hline $\begin{array}{l}\text { 5-phosphohydroxy-L- } \\
\text { lysine phospho-lyase }\end{array}$ & 1.974891 & 34.93728 & 4.144922 & Lysine degradation, Metabolic pathways & Generating Allysine \\
\hline $\begin{array}{l}\text { transcription factor CP2- } \\
\text { like protein } 1\end{array}$ & 33.3349 & 1.088583 & -4.93651 & & \\
\hline $\begin{array}{l}\text { serum/glucocorticoid } \\
\text { regulated kinase } 1\end{array}$ & 87.45664 & 1.841215 & -5.56984 & $\begin{array}{l}\text { FoxO signaling pathway, mTOR signaling pathway, } \\
\text { PI3K-Akt signaling pathway, Aldosterone-regulated so- } \\
\text { dium reabsorption }\end{array}$ & \\
\hline hypoxia up-regulated 1 & 135.8593 & 1.88101 & -6.17446 & Protein processing in endoplasmic reticulum & \\
\hline $\begin{array}{l}\text { Alcohol dehydrogenase } \\
{[N A D P(+)] \text { A }}\end{array}$ & 550.9179 & 101.9587 & -2.43385 & $\begin{array}{l}\text { Glycolysis / Gluconeogenesis, Pentose and } \\
\text { glucuronate interconversions, Glycerolipid metabolism, } \\
\text { Metabolic pathways }\end{array}$ & $\begin{array}{l}\text { Generating } \\
\text { glucuronate, ethanal } \\
\text { or D-Glyceraldehyde }\end{array}$ \\
\hline $\begin{array}{l}\text { Phosphatidate } \\
\text { phosphatase LPIN1 }\end{array}$ & 230.0628 & 21.91613 & -3.39196 & $\begin{array}{l}\text { Glycerolipid metabolism, Glycerophospholipid } \\
\text { metabolism, Metabolic pathways, mTOR signaling } \\
\text { pathway }\end{array}$ & \\
\hline $\begin{array}{l}\text { Copper-transporting } \\
\text { ATPase } 2\end{array}$ & 923.8284 & 210.7988 & -2.13176 & Mineral absorption & \\
\hline $\begin{array}{l}\text { calcium/calmodulin- } \\
\text { dependent serine } \\
\text { protein kinase }\end{array}$ & 55.2038 & 1.86159 & -4.89016 & Tight junction & \\
\hline $\begin{array}{l}\text { solute carrier family } 2, \\
\text { facilitated glucose }\end{array}$ & 16.81712 & 0.94255 & -4.15722 & Carbohydrate digestion and absorption & $\begin{array}{l}\text { Froctose or glucose } \\
\text { absorption }\end{array}$ \\
\hline
\end{tabular}


Table 1 Identification of differentially expressed gene based on transcriptome sequencing (Continued)

\begin{tabular}{|c|c|c|c|c|c|}
\hline Gene name & $\begin{array}{l}\mathrm{W} \\
\text { Expression }\end{array}$ & $\begin{array}{l}\mathrm{X}- \\
\text { Expression }\end{array}$ & $\begin{array}{l}\log _{2} \text { FoldChange } \\
(\mathrm{X} / \mathrm{W})\end{array}$ & KEGG map & Gene function \\
\hline $\begin{array}{l}\text { phosphoglycolate } \\
\text { phosphatase }\end{array}$ & 15.43525 & 0.934372 & -4.04609 & $\begin{array}{l}\text { Glyoxylate and dicarboxylate metabolism, Metabolic } \\
\text { pathways, Carbon metabolism }\end{array}$ & $\begin{array}{l}\text { Generating } \\
\text { glycolate }\end{array}$ \\
\hline $\begin{array}{l}\text { Nuclear receptor } \\
\text { coactivator } 7\end{array}$ & 31.91563 & 1.559127 & -4.35545 & RNA degradation & \\
\hline Plasma kallikrein & $20,520.24$ & 418.6751 & -5.61507 & Complement and coagulation cascades & \\
\hline $\begin{array}{l}\text { complement } \\
\text { component } 2\end{array}$ & 2119.225 & 73.06701 & -4.85817 & Complement and coagulation cascades, & \\
\hline
\end{tabular}

False Discovery Rate (FDR) $\leq 0.001$, Fold Change $\geq 1.00$

showed that metabolism, especially lipid metabolism, might contribute to the domestication of artificial diets, which was different from the domestication of dead prey fish, as the different constituents between dead prey fish and artificial diets.

We then analyzed the pathways in which the differential genes or metabolites were involved, the common pathways which showed the most enriched differential genes and metabolites, were retinol metabolism, glycerolipid metabolism and biosynthesis of unsaturated fatty acids. For retinol metabolism, retinol, 9-cis-retinol and 11-cis-retinol metabolites were higher in the Group X, consistently the $R D H$ (retinoldehydrogenase) gene expression was higher in the Group X, suggesting a better visual acuity in the mandarin fish which could be easy to accept artificial diets. Animals make food choices on the basis of the nutritional, physiological, environmental, and sociocultural factors [7], sensory system is of significance to food choices. It is critical for mandarin fish to catch prey fish though the perception of shape and motion with well-developed scotopic vision [13]. Salmo spp. shows the same motion and shape of food, they have high visual acuity, thus can feed swiftly by darting, the offered food pellet can be captured immediately before it falls down to the bottom of the tank [15-17]. Because of the low visual acuity and feeding only by stalking, mandarin fish can not recognize the prey before the time when food pellet fall to the bottom of tank, thus makes it difficult to feed mandarin fish with artificial diets [13]. The retinol metabolism dysfunction might be
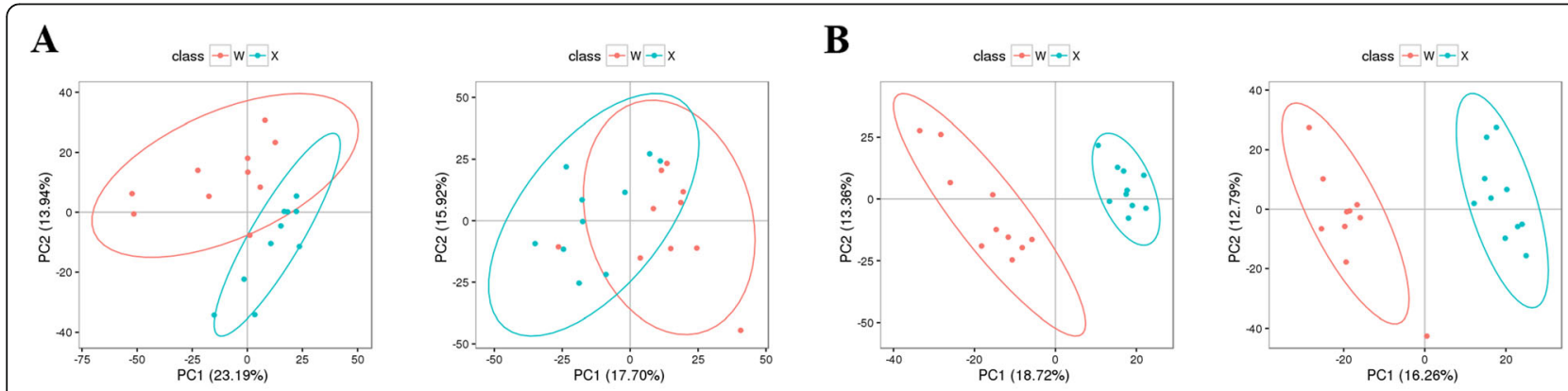

C

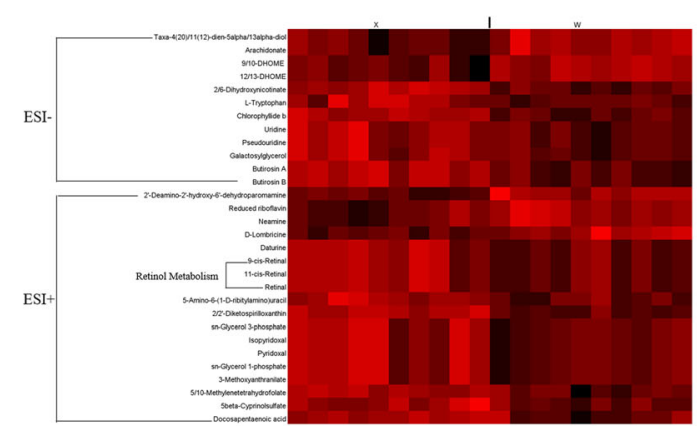

Fig. 2 a PCA scores scatter plot in positive ion (left) and in negative ion (right) scan modes for the two groups. b PLS-DA scores scatter plot in positive ion (left) and in negative ion (right) scan modes for the two groups. c The heat map of differential metabolites from the related pathways between the two groups in both positive and negative mode. Each line represents a differential metabolite and each cross represents a plasma sample group. Different colors represent different abundance intensity, and the higher abundance intensity shows a gradual increase from dark color to red color 
Table 2 Potential metabolomics biomarkers identified between the two groups

\begin{tabular}{|c|c|c|c|c|c|}
\hline Metabolities & RT (min) & $\mathrm{m} / \mathrm{z}$ & Score & Fragfentation sscore & VIP \\
\hline \multicolumn{6}{|l|}{ ESI+ } \\
\hline Isopyridoxal & 3.577216667 & 190.0465891 & 37.7 & 0.344 & 1.41246605 \\
\hline Pyridoxal & 3.577216667 & 190.0465891 & 37.6 & 0 & 1.41246605 \\
\hline sn-Glycerol 3-phosphate & 3.577216667 & 190.0465891 & 36.6 & 0 & 1.41246605 \\
\hline 5,10-Methylenetetrahydrofolate & 7.691483333 & 475.2050752 & 45.1 & 35.4 & 1.93838797 \\
\hline 5-Amino-6-(1-D-ribitylamino)uracil & 7.78 & 259.1044545 & 27.4 & 0 & 1.14846268 \\
\hline L-Hyoscyamine & 7.808933333 & 307.201348 & 38.8 & 5.95 & 1.50522082 \\
\hline 11-cis-Retinal & 7.808933333 & 307.201348 & 35.9 & 0 & 1.50522082 \\
\hline Littorine & 7.808933333 & 307.201348 & 38.8 & 5.95 & 1.50522082 \\
\hline Vitamin A aldehyde & 7.808933333 & 307.201348 & 35.9 & 0 & 1.50522082 \\
\hline 2,2'-Diketospirilloxanthin & 8.683883333 & 625.4260955 & 35.1 & 0 & 2.12500943 \\
\hline Docosapentaenoic acid & 7.603166667 & 313.2493985 & 35.2 & 0 & 1.8324347 \\
\hline Reduced riboflavin & 9.84055 & 361.1483341 & 36 & 0 & 2.03476142 \\
\hline sn-Glycerol 1-phosphate & 3.577216667 & 190.0465891 & 36.6 & 0 & 1.41246605 \\
\hline 2'-Deamino-2'-hydroxy-6'-dehydroparomamine & 7.588333333 & 305.132886 & 34.4 & 0.0568 & 1.25836276 \\
\hline Neamine & 9.84055 & 361.1483341 & 38.3 & 0 & 2.03476142 \\
\hline 3-Methoxyanthranilate & 3.577216667 & 190.0465891 & 38.5 & 4.38 & 1.41246605 \\
\hline 9-cis-Retinal & 7.808933333 & 307.201348 & 35.9 & 0 & 1.50522082 \\
\hline 5beta-Cyprinolsulfate & 7.897433333 & 550.3406162 & 37.1 & 6.39 & 1.88072292 \\
\hline D-Lombricine & 5.166666667 & 271.0812489 & 37.4 & 0 & 1.77701759 \\
\hline \multicolumn{6}{|l|}{ ESI- } \\
\hline L-Tryptophan & 3.5915 & 203.0817932 & 57.9 & 95.1 & 1.62394934 \\
\hline Arachidonate & 7.391183333 & 303.2325012 & 37.6 & 0 & 2.56862593 \\
\hline Uridine; & 1.374833333 & 243.061434 & 56.1 & 88.4 & 2.24617127 \\
\hline Taxa-4 (20),11 (12)-dien-5alpha,13alpha-diol & 7.391183333 & 303.2325012 & 56.1 & 92.4 & 2.56862593 \\
\hline Chlorophyllide b & 8.206233333 & 627.2113855 & 33.4 & 0 & 2.66318502 \\
\hline Galactosylglycerol & 1.395566667 & 289.0671401 & 37 & 0 & 2.13222525 \\
\hline (12Z)-9,10-Dihydroxyoctadec-12-enoic acid & 7.199016667 & 313.2378713 & 43.6 & 31.9 & 2.29817224 \\
\hline (9Z)-12,13-Dihydroxyoctadec-9-enoic acid & 7.199016667 & 313.2378713 & 43.6 & 31.9 & 2.29817224 \\
\hline Galactosylglycerol & 1.395566667 & 289.0671401 & 37 & 0 & 2.13222525 \\
\hline Pseudouridine & 1.374833333 & 243.061434 & 38.4 & 0 & 2.24617127 \\
\hline 2,6-Dihydroxynicotinate & 0.604766667 & 154.0141467 & 38.5 & 0.394 & 2.76092204 \\
\hline Butirosin B & 7.66915 & 554.2720652 & 36.1 & 0 & 3.08500393 \\
\hline Butirosin A & 7.66915 & 554.2720652 & 36.1 & 0 & 3.08500393 \\
\hline
\end{tabular}

Table 3 Identification of differential ions based on metabolome

\begin{tabular}{|c|c|c|c|c|c|c|c|c|c|c|}
\hline \multicolumn{5}{|l|}{ Differential ions } & \multicolumn{6}{|c|}{ Metabolites identification } \\
\hline \multirow{2}{*}{$\begin{array}{l}\text { Comparison among } \\
\text { groups }\end{array}$} & \multirow{2}{*}{$\begin{array}{l}\text { Detect } \\
\text { mode }\end{array}$} & \multirow{2}{*}{$\begin{array}{l}\text { Total ion } \\
\text { number }\end{array}$} & \multirow{2}{*}{$\begin{array}{l}\text { Up- } \\
\text { regulated }\end{array}$} & \multirow{2}{*}{$\begin{array}{l}\text { Down- } \\
\text { regulated }\end{array}$} & \multicolumn{3}{|c|}{ MS1 ions number } & \multicolumn{3}{|c|}{ MS2 ions number } \\
\hline & & & & & Total & $\begin{array}{l}\text { Up- } \\
\text { regulated }\end{array}$ & $\begin{array}{l}\text { Down- } \\
\text { regulated }\end{array}$ & Total & $\begin{array}{l}\text { Up- } \\
\text { regulated }\end{array}$ & $\begin{array}{l}\text { Down- } \\
\text { regulated }\end{array}$ \\
\hline \multirow[t]{2}{*}{$X$ vs W } & Positive & 127 & 86 & 41 & 44 & 32 & 12 & 20 & 16 & 4 \\
\hline & Negative & 116 & 65 & 51 & 24 & 17 & 7 & 11 & 7 & 4 \\
\hline
\end{tabular}

The number of all of the differential $\mathrm{m} / \mathrm{z}$ between the two groups, which including identified ions and unable identified ions

MS: the number of identified ions by searching KEGG database associated with primary data (parent ions)

MS2: the number of identified ions by searching fragmentation information available from KEGG database 


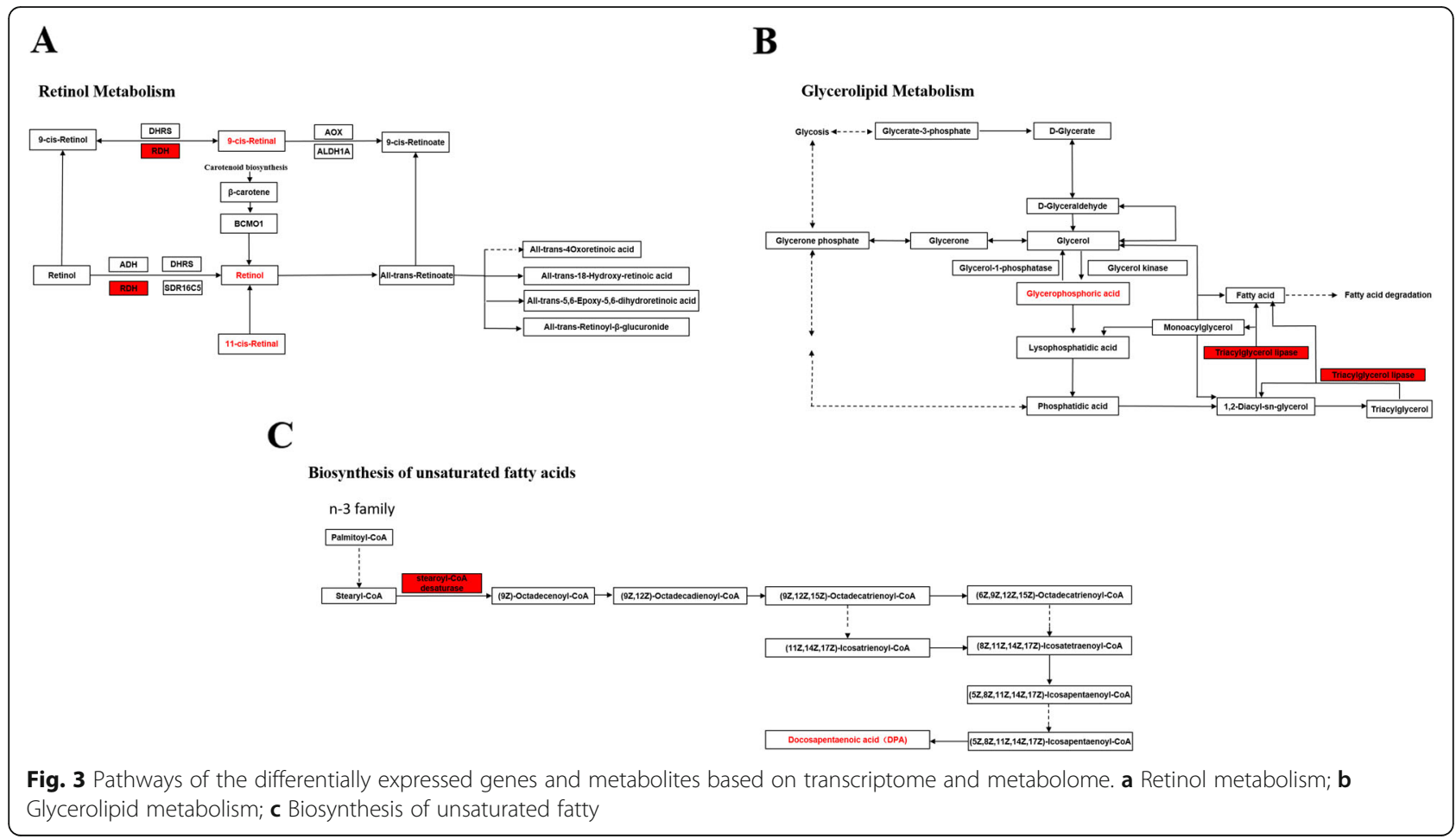

contributed to the lower visual ability in the mandarin fish which refused artificial diets.

In glycerolipid metabolism pathway, the gene expression of triacylglycerol lipase was higher in the mandarin fish of Group X, and the glycerophosphoric acid metabolite was also higher in the Group X. In the biosynthesis of unsaturated fatty acids pathway, stearoyl-CoA gene expression and docosapentaenoic acid (DPA) metabolite were higher in the Group X. These results suggested that mandarin fish which could accept artificial diets well, might be attributed to the better capacity of glycerolipid metabolism and unsaturated fatty acids biosynthesis. Live food diets (such as zooplankton) and dry formulated diets have different fat levels and influences in European grayling [18]. Artificial diets might have more fat and energy than live prey fish, suggesting that mandarin fish which accept artificial diets could make good use of fat, while the fish which refuse artificial diets could not.

To elucidate the regulatory mechanism of upregulated gene expression in the mandarin fish of Group $X$, we analyzed the differentially expressed genes based on transcriptome sequencing. The results showed TFIIF gene expression was significantly increased in the Group X. TFIIF communicates with a number of factors to regulate gene transcription. It has been reported that TFIIF directly binds to basal factors of TFIID, TFIIE and TFIIB [19]. TFIIF has been shown to be necessary for most, if not all, preinitiation complex formation and gene transcription [20, 21]. It suggested that in the mandarin fish which accepted artificial diets, the upregulated transcription of genes, involved in retinol metabolism, glycerolipid metabolism and biosynthesis of unsaturated fatty acids, might be contributed to the increased TFIIF expression.

To uncover why TFIIF was upregulated in the mandarin fish of Group X, the expressions of histone methyltransferases were analyzed based on transcriptome. The expression of histone-lysine $\mathrm{N}$-methyltransferase ezh1 was significantly decreased in the Group X. Histone methyltransferases EZH1 and EZH2 catalyze the trimethylation of H3K27, which serves as an epigenetic signal for chromatin condensation and transcriptional repression [22]. In mice, Ezh1 was required for neonatal heart regeneration after myocardial infarction and overexpression of Ezh1 promoted heart regeneration by upregulating cardiac muscle growth genes [23]. Furthermore, we observed the protein level of trimethylation of histone $\mathrm{H} 3$ at lysine 27 was lower in the Group X, suggesting an active function of gene expression. The decreased abundance of histone H3K27me3 was also found in FOXO1 (forkhead box protein O1) in HFD (high fat diets) fed rats, which persisted even after 8 weeks of diet reversal [24]. In addition, the total DNA methylation level of TFIIF was significantly higher in the mandarin fish of Group X than those of Group W. The mRNA level of TFIIF was higher in fish of Group X, our results showed a positive effect of DNA methylation on 


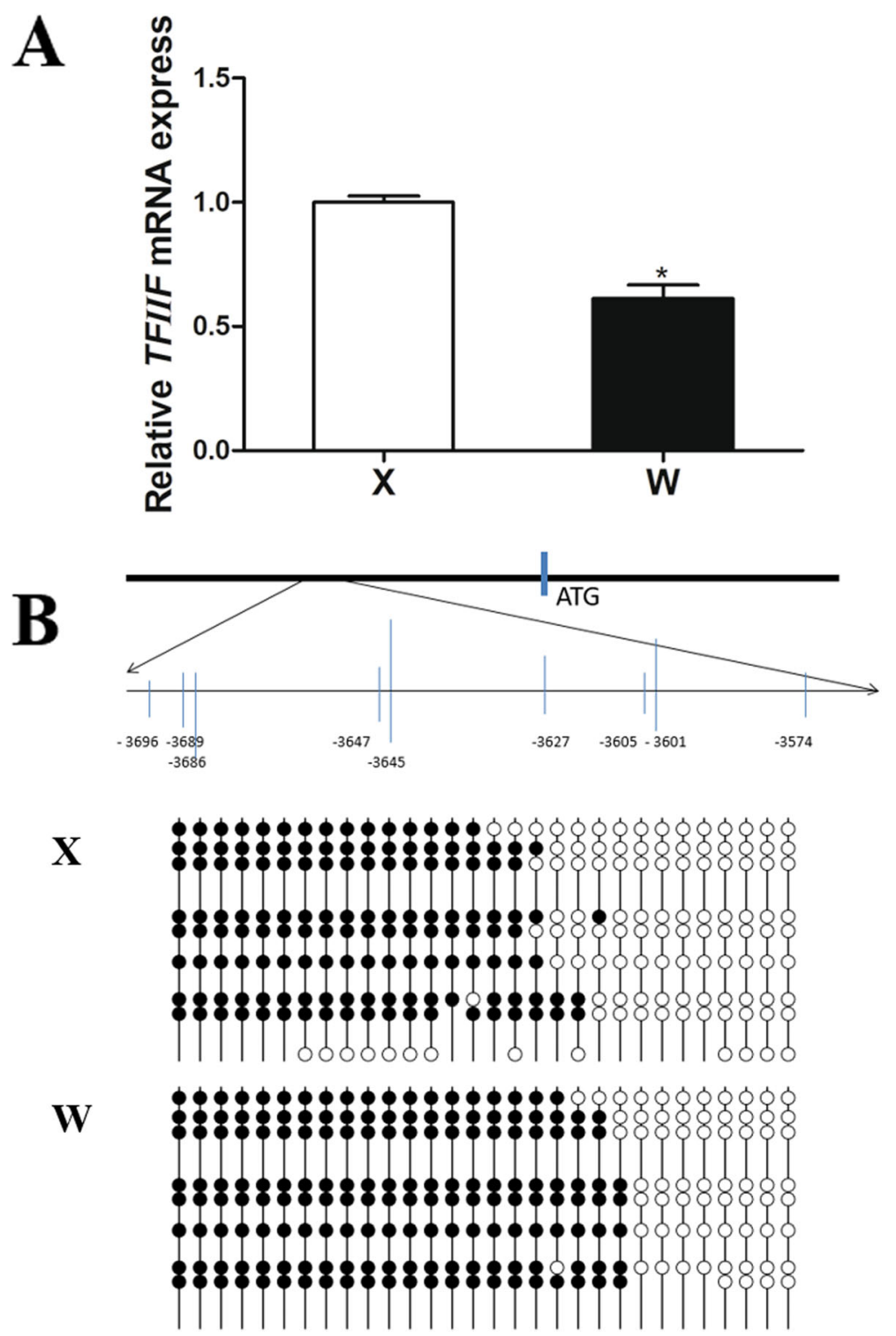

Fig. 4 TFIIF gene expression and DNA methylation. a TFIIF gene expression. b Illustration of the region of CpG islands sites, which includes 9 CpG sites, DNA methylation patterns of the two groups ( $X$ and $W$ ) analyzed by BSP. Each line represents one individual bacterial clone, and each circle represents one single CpG dinucleotide. Open circles show unmethylated CpGs and black circles show methylated CpGs

Table 4 Methylation of each CpG island of TFIIF gene between the two groups

\begin{tabular}{lllllllllll}
\hline CpG & $\mathbf{- 3 6 9 6}$ & $\mathbf{- 3 6 8 9}$ & $\mathbf{- 3 6 8 6}$ & $\mathbf{- 3 6 4 7}$ & $\mathbf{- 3 6 4 5}$ & $\mathbf{- 3 6 2 7}$ & $\mathbf{- 3 6 0 5}$ & $\mathbf{- 3 6 0 1}$ & $\mathbf{- 3 5 2 4}$ & total \\
Position & & & & & & & & & & \\
\hline ME-CPG & $9 / 30$ & $21 / 30$ & $21 / 30$ & $22 / 30$ & $22 / 30$ & $22 / 30$ & $21 / 30$ & $22 / 30$ & $0 / 0$ & $170 / 23672.0 \%$ \\
X & $63.3 \%$ & $70.0 \%$ & $70.0 \%$ & $73.3 \%$ & $73.3 \%$ & $73.3 \%$ & $70.0 \%$ & $84.6 \%$ & $0.0 \%$ & \\
ME-CPG & $15 / 3050.0 \%$ & $18 / 30$ & $17 / 30$ & $19 / 30$ & $17 / 30$ & $18 / 30$ & $19 / 30$ & $19 / 29$ & $0 / 13$ & $142 / 25256.3 \%$ \\
W & & $60.0 \%$ & $56.7 \%$ & $63.3 \%$ & $56.7 \%$ & $60.0 \%$ & $63.3 \%$ & $65.5 \%$ & $0.0 \%$ & \\
significance & 0.114 & 0.417 & 0.284 & 0.405 & 0.176 & 0.273 & 0.584 & 0.105 & $\backslash$ & $0.000^{*}$ \\
\hline
\end{tabular}



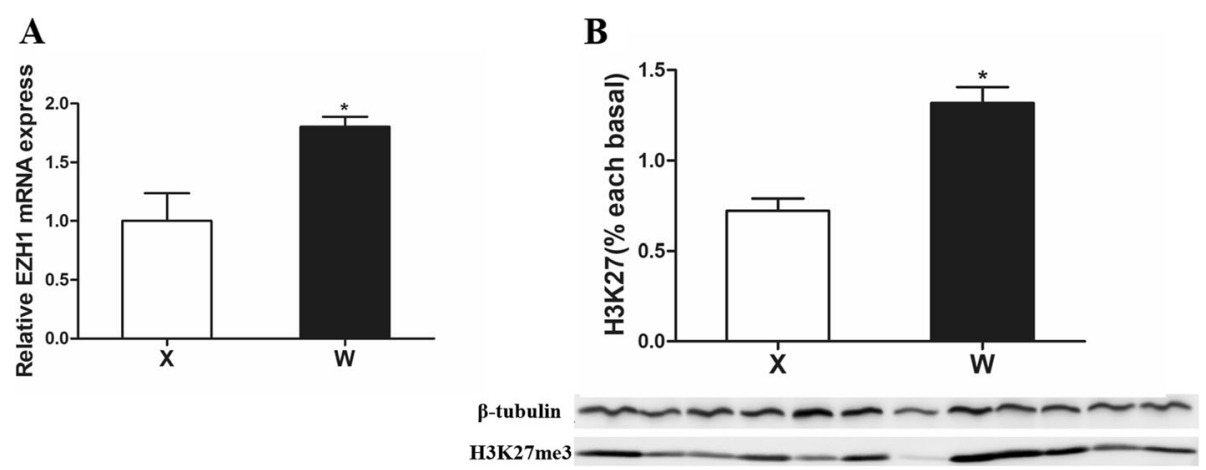

Fig. 5 a Validation of ezh1 mRNA expression. b The H3K27me3 protein level of between Group X and W. Data are mean \pm SEM $(n=6)$, significant difference is marked with an asterisk $(P<0.05)$

gene expression. In soybean, the genome-wide methylation profiles showed that hyper-methylated genes had higher gene expression [25], in ventricular septal defect patients, genome-wide DNA methylation data showed 12 hypermethylated genes had a higher gene expression [26]. In Arabidopsis, upon loss of CpG methylation, there was target-specific enrichment of H3K27me3 in heterochromatin that correlated with transcriptional reactivation, it is suggested that there was an antagonistic effect between CpG methylation and H3K27me3 [27]. It is hypothesized that the lower ezh1 expression in the mandarin fish of Group X, could be contributed to the decreased methylation at 'Lys-27' of histone H3, and then up-regulating the expression and methylation of TFIIF gene.

\section{Conclusions}

Our research indicated the individual differences of acceptance on artificial diets in mandarin fish and the potential molecular mechanism. The mandarin fish which feed on artificial diets, could down-regulate the ezh1 expression, repressing the tri-methylation level of histone $\mathrm{H} 3$ at lysine 27, and then resulting in the increased DNA methylation and mRNA expression of TFIIF gene. TFIIF as an important transcription factor, might regulate the expression of genes involved in retinol metabolism, glycerolipid metabolism and glycerophosphoric metabolism, and modify the acceptance on artificial diets of mandarin fish. These results suggested the potential effect of histone methylation on food habits domestication in mandarin fish.

\section{Methods}

\section{Fish domestication and sampling}

Mandarin fish $(69.9 \pm 10.2 \mathrm{~g})$ were obtained from Chinese Perch Research Center of Huazhong Agricultural University (Wuhan, Hubei Province, China) and maintained in the aquarium (12 tanks, 50 fish per tank) at constant temperature $\left(25 \pm 0.5^{\circ} \mathrm{C}\right)$. Mandarin fish were and domesticated and fed with artificial diets (Table 5) and divided into two groups: fish did not eat artificial diets and fish ate artificial diets. The fish did not eat artificial diets during the first domestication process was then fed with live fish prey for three days, starved for two days and fed with artificial diets for one day, and then we selected the fish did not eat artificial diets during the second domestication process and repeated the domestication process for one more time. The fish ate artificial diets during the first domestication process was fed with live fish prey for one days and fed with artificial diets for three days, then we selected the fish ate artificial diets during the second domestication process and repeated the domestication process for one more time. Finally, the two groups were obtained, the fish did not eat artificial diets or ate artificial diets during all of the three domestication processes, named Group W $(n=56)$ or X $(n=24)$, respectively. Six fish were used for real-time quantitative PCR. Six fish were used for western blotting. Ten fish were used for metabolome, and three fish were used for transcriptome sequencing.

Table 5 Composition of artificial diets

\begin{tabular}{ll}
\hline Ingredients & $\%$ \\
\hline White fish meal & 71 \\
Corn starch & 8 \\
Fish oil & 10 \\
Vitamin premix & 2 \\
Mineral premix & \\
Microcrystalline cellulose & 2 \\
Carboxymethyl cellulose & 2 \\
Yeast extract powder & 2 \\
\hline
\end{tabular}

Note: 1. Vitamin premix (per $\mathrm{kg}$ of diet): vitamin B1 (thiamin), $30 \mathrm{mg}$; vitamin B2 (riboflavin), $60 \mathrm{mg}$; vitamin B6, $30 \mathrm{mg}$; vitamin B12, $0.22 \mathrm{mg}$; vitamin D3, 5 $\mathrm{mg}$; vitamin E $160 \mathrm{mg}$; vitamin $\mathrm{K} 350 \mathrm{mg}$; folic acid, $20 \mathrm{mg}$; biotin, $2.5 \mathrm{mg}$; pantothenic acid calcium, $100 \mathrm{mg}$; ascorbic acid (35\%), $250 \mathrm{mg}$; niacinamide, $200 \mathrm{mg}$; powdered rice hulls, $999 \mathrm{mg}$

2. Mineral premix (per kg of diet): MnSO4, $10 \mathrm{mg} ; \mathrm{MgSO} 4,10 \mathrm{mg} ; \mathrm{KCl}, 95 \mathrm{mg}$; $\mathrm{NaCl}, 165 \mathrm{mg} ; \mathrm{ZnSO} 4,20 \mathrm{mg}$ KI, $1 \mathrm{mg}$; CuSO4, $12.5 \mathrm{mg}$; FeSO4, $105 \mathrm{mg}$ $\mathrm{Na} 2 \mathrm{SeO}, 0.1 \mathrm{mg} ; \mathrm{Co}, 1.5 \mathrm{mg}$ 
The experimental fish were anesthetized with MS-222 (200 mg/L) (Redmond, WA, USA) and sacrificed by decapitation according to the ethical guidelines of Huazhong Agricultural University. Immediately after the surgical resection, the liver tissue was frozen in liquid nitrogen and stored at $-80^{\circ} \mathrm{C}$ until used. The blood was drawn from the tail vein. The plasma was obtained from whole blood sample separated with $4000 \mathrm{r} /$ centrifuge for $10 \mathrm{~min}$. The animal protocol was approved by the Institutional Animal Care and Use Ethics Committee of Huazhong Agricultural University (Wuhan, China) (HZAUFI-2017-015).

\section{RNA isolation and reverse transcription}

Total RNA was extracted using Trizol reagent, and one microgram of total RNA was synthesized to complementary DNA (cDNA) by Revert Aid ${ }^{\mathrm{sm}}$ Reverse Transcriptase (TaKaRa, Tokyo, Japan). The protocols were following the manufacturer's instructions.

\section{Transcriptome sequencing}

For transcriptome analysis, the equal amount of total RNA was used to construct the libraries for each group $(n=3)$ using MGIEasy RNA kit (BGI, Wuhan, China). The paired-end cDNA libraries were constructed and sequenced using BGISEQ-500 system (BGI, Wuhan, China). The processes of image deconvolution, base calling, unigene assembly, annotation and expression level estimation were carried out as described by You et al. [28]. The differentially expressed genes were identified as DEGseq method described before [29], and the significance of gene expression difference was judged with Fold Change $\geq 2.00$ and FDR (False Discovery Rate) $\leq$ 0.001 as the threshold. The analysis of GO function and KEGG pathway of differentially expressed genes were carried out.

\section{Metabolome}

Serum samples (40 $\mu \mathrm{l}$, including QC samples) were added to new Eppendorf tubes with ice-cold methanol $(120 \mu \mathrm{l})$, vortex mixed for $1 \mathrm{~min}$, placed in holding for $30 \mathrm{~min}$ at $-20^{\circ} \mathrm{C}$, and centrifuged at $4000 \mathrm{~g}$ for $20 \mathrm{~min}$ at $4{ }^{\circ} \mathrm{C}$. $25 \mu \mathrm{l}$ of supernatant and $225 \mu \mathrm{l} 50 \%$ methanol were mixed. Then $20 \mu \mathrm{l}$ of mixture from each sample were mixed as quality control samples, $60 \mu \mathrm{l}$ of mixture was conducted as samples. All samples were stored at $80^{\circ} \mathrm{C}$ (ten biological replicates for each group).

All samples were acquired by the LC-MS system followed machine orders. Chromatographic separations were performed using an ultra performance liquid chromatography (UPLC) system (Waters, USA) and a highresolution tandem mass spectrometer SYNAPT G2 XS QTOF (Waters, USA) was used to detect metabolites as the methods described by Huang et al. [30]. The mass spectrometry data were acquired in Centroid MSE mode. Statistical analysis was performed as previous [31]. Putative metabolites were first derived by searching the exact molecular mass data from redundant $\mathrm{m} / \mathrm{z}$ peaks against the online HMDB (http://www.hmdb.ca/), METLIN (http://metlin.scripps.edu/) and KEGG (www. genome.jp/kegg/) databases.

\section{Real-time quantitative PCR}

We searched the cDNA sequences from transcriptome data of mandarin fish, designed the primers with Primer 5.0 software (Table 6). The potential housekeeping gene according to the literature [32], beta-actin, b2m, rpl13a, and $h m b s$ were examined, and Rpl13a gene was more stable and selected as the internal control. Real-time quantitative PCR was performed with $\mathrm{MyiQ}^{\mathrm{m}} 2$ TwoColor Real-Time PCR Detection System (Bio-Rad, Hercules, USA) as the methods described by Liang et al. [33]. The target gene expression relative to rpl13a expression were calculated by the optimized comparative Ct $\left(2^{-\Delta \Delta C t}\right)$ value method [34]. Data with six biological replicates and three technical replicates were presented as mean \pm S.E.M.

\section{DNA methylation analysis}

TIANamp Genomic DNA Kit (Tiangen, Beijing, China) was used for Genomic DNA extraction, and then the DNA was treated with sodium bisulfite by EZ DNA Methylation Kit (Zymo Research, USA). The BSP primers were designed by the online MethPrimer software 14 and Primer 5.0 (Table 6). As the methods described by Cai et al. [35], PCR products were subcloned and sequenced. Six samples from the mandarin fish of Group W or X were analyzed with five technical replicates.

\section{Western blotting}

The proteins from liver tissue were separated on 10\% SDS-PAGE gel and transferred onto PVDF membrane. Tri-Methyl-Histone H3 (lys27) (C36B11) Rabbit mAb

Table 6 Nucleotide sequences of the primers

\begin{tabular}{ll}
\hline Primers for real-time PCR & Sequences(5'-3') \\
\hline RPL13A-F & CACCCTATGACAAGAGGAAGC \\
RPL13A-R & TGTGCCAGACGCCCAAG \\
EZH1-F & AAAAGATTGAGCAGCAGACA \\
EZH1-R & GGAAGCCAAACTCCACTGTA \\
TFIIF-F & GTGCCCAAATACCTCTCTCAGC \\
TFIIF-R & TCTATACCCTCAATCACAGTCAGC \\
Primers for BSP amplicon & Sequences(5'-3') \\
BSP TFIIF-F & TTAGGGTTTGATTTTGTTITIT \\
BSP TFIIF-R & ACTAAATAAACAACTCTTCATTITAC \\
\hline
\end{tabular}


was obtained from Cell Signaling Technology (Danvers, MA). The protein level H3K27me3 were detected by western blotting with the antibody (1:1000-1:4000) according to manufacturer's instructions. Blots were probed by second antibody labeled with IR-Dye 680 or $800 \mathrm{cw}$ (1:2000-1:4000, Licor, Lincoln, NE, USA) and the membranes were visualized and quantified as the methods described by You et al. [28]. (six biological replicates for each group).

\section{Statistical analysis}

SPSS 19.0 software was used for the statistical analyses. The normality and homogeneity of variances were tested using the Shapiro-Wilk's test and Levene's test, respectively. The significant differences were found using oneway analysis of variance (ANOVA), followed by Duncan's multiple range tests and Fisher's least significant difference post hoc test. Differences with $P<0.05$ were considered to be significant.

\section{Abbreviations}

EZH1: Histone H3-lysine27 N-trimethyltransferase EZH1; H3K27me3: Histone H3-lysine27 tri-methylation; TFIIF: General transcription factor IIF; NPY: Neuropeptide Y; AgRP: Agouti-related protein; Tas1r1: Taste receptor type 1 member 1; PKD1L3: Polycystic kidney disease 1-like 3; PKD2L1: Polycystic kidney disease 2-like 1; RNASE1: Pancreatic ribonuclease: B2m: Beta-2-microglobulin; Rpl13a: Ribosomal protein L13a; Hmbs: Hydroxymethylbilane synthase; QC: Quality control; PCA: Principal component analysis; LC-MS: Liquid chromatography mass spectrometry; KEGG: Kyoto Encyclopedia of Genes and Genomes; RDH: Retinol dehydrogenase; DPA: Docosapentaenoic acid; GO: Gene Ontology; FOXO1: Forkhead box protein O1; HFD: High fat diets; UPLC: Ultra performance liquid chromatography; FDR: False Discovery Rate; ANOVA: Oneway analysis of variance

\section{Acknowledgments}

Not applicable.

\section{Authors' contributions}

S.H., J.J.Y., Z.L.Z. and Y.P.Z. contributed to the sample preparation and examination. S.H. and L.L. performed the assembly and bioinformatical analysis. S.H. and J.J.Y. performed the data analysis. S.H. and X.F.L. gave technical advice and contributed to the study design. S.H. and J.J.Y. wrote the paper. All authors read and approved the final manuscript.

\section{Funding}

This work was financially supported by the China Agriculture Research System (CARS-46), the National Natural Science Foundation of China (31772822), and the Open Project of Anhui Province Key Laboratory of Aquaculture \& Stock Enhancement (AHSC202002).

\section{Availability of data and materials}

The sequencing data in this study have been deposited in the Sequence Read Archive (SRA) database (accession number: PRJNA613186).

\section{Ethics approval and consent to participate}

The animal protocol was approved by the Institutional Animal Care and Use Ethics Committee of Huazhong Agricultural University (Wuhan, China) (HZAUFI-2017-015).

\section{Consent for publication}

Not applicable.

\section{Competing interests}

The authors declare that they have no conflict of interest.

\section{Author details}

'College of Fisheries, Chinese Perch Research Center, Huazhong Agricultural University, 1 Shizishan Street, Wuhan 430070, Hubei, China. ${ }^{2}$ Innovation Base for Chinese Perch Breeding, Key Lab of Freshwater Animal Breeding, Ministry of Agriculture, Wuhan 430070, China. ${ }^{3}$ Anhui Province Key Laboratory of Aquaculture \& Stock Enhancement, Fishery Institute of Anhui Academy of Agricultural Sciences, Hefei 230031, China.

Received: 27 March 2020 Accepted: 22 January 2021

Published online: 22 February 2021

\section{References}

1. Liang XF, Lin X, Li S, Liu JK. Impact of environmental and innate factors on the food habit of Chinese perch Siniperca chuatsi (Basilewsky) (Percichthyidae). Aquac Res. 2008;39:150-7.

2. He S, Liang XF, Sun J, Li L, Yu Y, HuangW Q. CM, Cao L, Bai XL, Tao YX. Insights into food preference in hybrid f1 of siniperca chuatsi $(+) \times$ siniperca

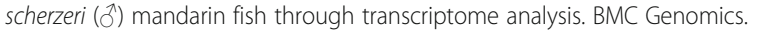
2013;14.

3. Morton GJ, Cummings DE, Baskin DG, Barsh GS, Schwartz MW. Central nervous system control of food intake and body weight. Nature. 2006;443: 289-95.

4. Cone RD. Anatomy and regulation of the central melanocortin system. Nat Neurosci. 2005:8:571-8.

5. Zhao H, Yang JR, Xu H, Zhang J. Pseudogenization of the umami taste receptor gene Tas $1 \mathrm{r} 1$ in the giant panda coincided with its dietary switch to bamboo. Mol Biol Evol. 2010;27:2669-73.

6. Li R, Fan W, Tian G, Zhu H, He L, Cai J, Huang Q, Cai Q, Li B, Bai Y, et al. The sequence and de novo assembly of the giant panda genome. Nature. 2010; 463:311-7.

7. Garcia-Bailo B, Toguri C, Eny KM, El-Sohemy A. Genetic variation in taste and its influence on food selection. OMICS. 2009;13:69-80.

8. Zhang J, Zhang YP, Rosenberg HF. Adaptive evolution of a duplicated pancreatic ribonuclease gene in a leaf-eating monkey. Nat Genet. 2002;30: 411-5.

9. Johnson IT, Belshaw NJ. Environment, diet and cpg island methylation: epigenetic signals in gastrointestinal neoplasia. Food Chem Toxicol Int Published Br Industrial Biol Res Assoc. 2008;46(4):0-1359.

10. Wolff $G L$, Kodell RL, Moore SR, Cooney CA. Maternal epigenetics and methyl supplements affect agouti gene expression in Avy/a mice. FASEB J. 1998;12: 949-57.

11. Cooney CA, Dave AA, Wolff GL. Maternal methyl supplements in mice affect epigenetic variation and DNA methylation of offspring. J Nutr. 2002;132: 23935-400S.

12. Begum G, Stevens A, Smith EB, Connor K, Challis JRG, Bloomfield F, White A. Epigenetic changes in fetal hypothalamic energy regulating pathways are associated with maternal undernutrition and twinning. FASEB J. 2012;26(4): 1694-703.

13. Liang XF, Liu JK, Huang BY. The role of sense organs in the feeding behaviour of Chinese perch. J Fish Biol. 1998:52:1058-67.

14. Liang X, Oku H, Ogata H, Liu J, He X. Weaning Chinese perch Siniperca chuatsi (Basilewsky) onto artificial diets based upon its specific sensory modality infeeding. Aquac Res. 2001;32:76-82.

15. Irvine JR, Northcote TG. Selection by young rainbow trout (Salmo gairdneri) in simulated stream environments for live and dead prey of different sizes. Can J Fish Aquat Sci. 1983;40:1745-9.

16. Stradmeyer L, Metcalfe NB, Thorpe JE. Effect of food pellet shape and texture on the feeding response of juvenile Atlantic salmon. Aquaculture. 1988;73:217-28.

17. Stradmeyer L. A behavioural method to test feeding responses of fish to pelleted diets. Aquaculture. 1989;79:303-10.

18. Carlstein M. Natural food and artificial, dry starter diets: effects on growth and survival in intensively reared European grayling. Aquac Int. 1993;1(2): $112-23$.

19. McEwan IJ, Gustafsson J. Interaction of the human androgen receptor transactivation function with the general transcription factor TFIIF. Proc Natl Acad Sci U S A. 1997;94:8485-90.

20. Tan S, Conaway RC, Conaway JW. Dissection of transcription factor TFIIF functional domains required for initiation and elongation. Proc Natl Acad Sci U S A. 1995;92:6042-6. 
21. Killeen MT, Greenblatt JF. The general transcription factor RAP30 binds to RNA polymerase II and prevents it from binding nonspecifically to DNA. Mol Cell Biol. 1992;12:30-7.

22. Lui JC, Garrison P, Nguyen Q, Ad M, Keembiyehetty C, Chen W, et al. Ezh1 and ezh2 promote skeletal growth by repressing inhibitors of chondrocyte proliferation and hypertrophy. Nat Commun. 2016;7:13685.

23. Ai S, Yu X, Li Y, Peng Y, Li C, Yue Y, et al. Divergent requirements for ezh1 in heart development versus regeneration. Circ Res. 2017;121:106-12.

24. Kumar S, Pamulapati H, Tikoo K. Fatty acid induced metabolic memory involves alterations in renal histone h3k36me2 and h3k27me3. Mol Cell Endocrinol. 2015:422:233-42.

25. Yanwei L, Xianlong D, Xuan W, Tingting H, Hao Z, Longshu Y, et al. Genome-wide comparative analysis of dna methylation between soybean cytoplasmic male-sterile line njcms5a and its maintainer njcms5b. BMC Genomics. 2017;18(1):596.

26. Marcel G, Cornelia D, Huanhuan C, llona D, Kerstin S, Sophia S, et al. Comparative dna methylation and gene expression analysis identifies novel genes for structural congenital heart diseases. Cardiovasc Res. 2016;112:46477.

27. Mathieu O, Probst AV, Paszkowski J. Distinct regulation of histone h3 methylation at lysines 27 and 9 by cpg methylation in arabidopsis. EMBO $J$. 2005;24(15):2783-91.

28. You JJ, Ren P, He S, Liang XF, Zhang YP. Histone methylation of h3k4 involved in the anorexia of carnivorous mandarin fish (siniperca chuatsi) after feeding on a carbohydrate-rich diet. Front Endocrinol. 2020;11:323.

29. Wang $L$, Feng $Z$, Wang $X$, Wang $X$, Zhang $X$. DEGseq, an $R$ package for identifying differentially expressed genes from RNA-seq data. Bioinformatics. 2010;26(1):136-8.

30. Huang JF, Shen ZY, Mao QL, Zhang XM, Zhang B, Wu JS, et al. Systematic analysis of bottlenecks in a multibranched and multilevel regulated pathway: the molecular fundamentals of I-methionine biosynthesis in Escherichia coli. ACS Synth Biol. 2018;7:2577-89.

31. Zhou LF, Zhao BW, Guan NN, et al. Plasma metabolomics profiling for fish maturation in blunt snout bream. Metabolomics. 2017;13(4):40.

32. Vandesompele J, Preter KD, Pattyn F, Poppe B, Roy NV, Paepe AD. Accurate normalization of real-time quantitative RT-PCR data by geometric averaging of multiple internal control genes. Genome Biol. 2018;3:1-12.

33. Liang H, He S, Liang XF, Lu HL, Chen K. Feeding habit transition induced by social learning through CAMKII signaling in chinese perch (siniperca chuatsi). Aquaculture. 2020;533:736211.

34. Livak KJ, Schmittgen TD. Analysis of relative gene expression data using realtime quantitative PCR and the 2- $\Delta \Delta C T$ method. Methods. 2001;25:402-8.

35. Cai WJ, He S, Liang XF, Yuan XC. DNA methylation of T1R1 gene in the vegetarian adaptation of grass carp ctenopharyngodon idella. Sci Rep. 2018; 8:6934.

\section{Publisher's Note}

Springer Nature remains neutral with regard to jurisdictional claims in published maps and institutional affiliations.

Ready to submit your research? Choose BMC and benefit from:

- fast, convenient online submission

- thorough peer review by experienced researchers in your field

- rapid publication on acceptance

- support for research data, including large and complex data types

- gold Open Access which fosters wider collaboration and increased citations

- maximum visibility for your research: over $100 \mathrm{M}$ website views per year

At BMC, research is always in progress.

Learn more biomedcentral.com/submissions 